\title{
Validation of fracture envelopes of structural adhesives for mixed- mode strength prediction of bonded joints
}

\author{
J.P.S.M.B. Ribeiro \\ Departamento de Engenharia Mecânica, Instituto Superior de Engenharia do Porto, Instituto Politécnico do Porto, Portugal \\ 1120523@isep.ipp.pt
}

R.D.S.G. Campilho

Departamento de Engenharia Mecânica, Instituto Superior de Engenharia do Porto, Instituto Politécnico do Porto, Portugal INEGI - Pólo FEUP

raulcampilho@gmail.com, bttps://orcid.org/0000-0003-4167-4434

R.J.B. Rocha

INEGI - Pólo FEUP, Portugal

ricardojbragarocha@gmail.com

\author{
A.J.S. Leal, F.A.L. Viana \\ Departamento de Engenharia Mecânica, Instituto Superior de Engenharia do Porto, Instituto Politécnico do Porto, Portugal \\ alb.leal@gmail.com,1120367@isep.ipp.pt
}

\begin{abstract}
In the design of adhesive structures, it is extremely important to accurately predict their strength and fracture properties (critical strain energy release rate in tension, $G_{\mathrm{IC}}$, and shear, $G_{\mathrm{IIC}}$. In most cases, the loads occur in mixed-mode (tension plus shear). Thus, it is of great importance the perception of fracture in these conditions, namely of the strain energy release rates in tension, $G_{\mathrm{I}}$, and shear, $G_{\mathrm{II}}$, relative to different crack propagation criteria or fracture envelopes. This comparison allows to determine the most suitable energetic propagation criterion to be used in cohesive zone models (CZM). The main objective of this work is to verify, by CZM, which is the power parameter $(\alpha)$ that best suits the energetic crack propagation criterion for CZM modelling, using single-lap joints (SLJ) and double-lap joints (DLJ) with aluminium adherends and bonded with three different adhesives. With this purpose, numerical simulations of the SLJ and DLJ are carried out, and the maximum load $\left(P_{\mathrm{m}}\right)$ is compared with experiments. For the Araldite ${ }^{\mathbb{B}}$ AV138 and Araldite ${ }^{\circledR}$ 2015, the energetic criterion resulting from the experimental work provided matching numerical results and, thus, the fracture envelopes were validated. The Sikaforce ${ }^{\circledR} 7752$ results were slightly offset due to CZM law shape issues.
\end{abstract}

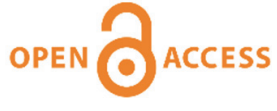

Citation: Ribeiro, J.P.S.M.B., Campilho, R.D.S.G., Rocha, R.J.B., Leal, A.J.S., Viana, F.A.L., Validation of fracture envelopes of structural adhesives for mixed-mode strength prediction of bonded joints, Frattura ed Integrità Strutturale, 48 (2019) 332-347.

Received: 24.09 .2018

Accepted: 28.10 .2018

Published: 01.04.2019

Copyright: (C) 2019 This is an open access article under the terms of the CC-BY 4.0, which permits unrestricted use, distribution, and reproduction in any medium, provided the original author and source are credited. 
KEYWORDS. Bonded joint; Finite Element analysis; Cohesive zone models; Mixed-mode fracture; Fracture envelope.

\section{INTRODUCTION}

I $\mathrm{n}$ the present time, adhesively-bonded joints are used in numerous industrial fields due to several advantages over other joining methods, e.g. welding, riveting and fastening. In fact, from a simple shoe to a space shuttle, adhesives are employed to bond similar and dissimilar materials. The aeronautic industry, continuously looking for new techniques to reduce fuel consumption and costs, was the one that most contributed to the development of adhesive joints [1]. Moreover, the use of composite materials such as carbon fibre reinforced polymers (CFRP) in structures has significantly increased during the last years. In the automotive industry, CFRP is usually joined to other composites, aluminium or steel through adhesive bonds [2]. This technique's advantages include preserving the integrity of the parent materials, since it avoids any structural damage (i.e. no holes or heating), thus providing a better stress distribution along the bonded area [3]. Additionally, improved strength-weight and cost-effectiveness ratios can be attained, which are highly relevant for the industry and designers in the pursuit of better products [1]. Few other benefits such as flexible gap filing, noise and vibration damping, excellent insulation and improved aesthetics are inherent to this method. Nevertheless, some drawbacks still persist, such as the requirement of a surface treatment, disassembly issues without causing damage, low resistance to temperature and humidity, and joint design orientated towards the elimination of peel stresses [4]. A number of joint architectures is available depending on the different applied loads. Among those, the SLJ is the most studied one. In fact, SLJ are simple to manufacture, although the adherends are not aligned, causing major peel $\left(\sigma_{\mathrm{y}}\right)$ stresses at the overlap ends [3]. The DLJ, slightly more difficult to produce, manages to decrease the bending moment due to its balanced design, thus reducing both $\sigma_{\mathrm{y}}$ and shear $\left(\tau_{\mathrm{xy}}\right)$ stresses. Despite that, internal bending moments may occur, triggering $\sigma_{\mathrm{y}}$ stresses at the ends of the inner adherend. The scarf joint, which also presents manufacturing difficulties (in cutting the taper angle) keeps the loading axis collinear with the joint, therefore promoting more uniform $\sigma_{\mathrm{y}}$ stresses in the adhesive layer and helping the joint to endure higher strengths compared to lap joints [5]. Moreover, one may find commonly other joint architectures, such as butt, strap, step, tubular and T-joints.

The development of trustworthy predictive methods is required for a widespread use of adhesively-bonded joints. Despite few analytical solutions being capable to quickly predict the joints' behaviour, the process could become extremely complex when composite adherends are used or in the presence of adhesives with high plasticity. The Finite Element (FE) method is capable to overcome such issues and is by far the most common technique used in bonded joints [6]. Several approaches were developed along the years, such as continuum mechanics, fracture and damage mechanics techniques. Later, during the sixties, Barenblatt [7] and Dugdale [8] proposed the concept of cohesive zone to describe damage under static loads. This method simulates the damage along a predefined crack path thru the establishment of a load-displacement $(P-\delta)$ correlation, known as traction-separation law. These laws associate the cohesive tractions $\left(t_{\mathrm{n}}\right.$ for tension and $t_{\mathrm{s}}$ for shear) with the relative displacements ( $\delta_{\mathrm{n}}$ for tension and $\delta_{\mathrm{s}}$ for shear). To obtain good agreement between the predicted strength and the experiments, a truthful estimation of the cohesive strengths in tension and in shear $\left(t_{\mathrm{n}}{ }^{0}\right.$ and $t_{\mathrm{s}}{ }^{0}$, respectively), and $G_{\text {IC }}$ and $G_{\text {IIC }}$ is essential. Usually, an adhesive joint may be put under $\sigma_{\mathrm{y}}$ or $\tau_{\mathrm{xy}}$ stresses, although in most cases it is subjected simultaneously to both, thereby creating a mixed-mode loading. Despite the importance of the correct estimation of the CZM parameters, standardized methods are not yet available [9]. Nevertheless, few techniques are available to assess the cohesive parameters: the property identification method, the direct method and the inverse method [1]. The property identification technique involves the separated calculation of each one of the cohesive law parameters by proper tests. This approach is particularly critical if bulk tests are used due to reported deviations between the bulk and thin adhesive bond cohesive properties [10]. The direct method provides the precise shape and the complete CZM laws by measuring the $J$ integral and crack-tip normal or shear displacements, through the differentiation of $G_{\mathrm{I}}$ or $G_{\mathrm{II}}$ with respect to $\delta_{\mathrm{n}}$ or $\delta_{\mathrm{s}}$, respectively [11]. On the other hand, the inverse method involves estimating the CZM parameters by iterative fitting the FE prediction with experimental data (e.g. the R-curve, the crack opening profile or the $P$ - $\delta$ curve), considering a precise description of the experimental geometry and approximated cohesive laws [12]. The value of GIC or GIIC is input in the FE model and, to completely define the CZM law, approximate bulk values can be used for $t_{n}^{0}$ or $t_{n}$ s for the initiation of the trial and error iterative process. 
Several tensile fracture characterization tests to evaluate $G_{I C}$ are available, such as the Double-Cantilever Beam (DCB), the Tapered Double-Cantilever Beam (TDCB), the Compact Tension (CT) and the Single-Edge Notched Bending (SENB). The DCB test became the most used, being supported by the BSI 7991:20001 [13], ASTM D3433 [14] and ISO 25217 [15] standards, providing guiding processes for the experiments and data reduction. This test requires an initial crack introduced during the fabrication process at the adhesive-free edge of the specimen, which will propagate by applying an opening load at the specimen's edge. The R-curve plots the $G_{\mathrm{I}}$ against the crack length $(a)$. In theory, this curve provides a perfectly horizontal $G_{\mathrm{I}}-a$ curve during damage growth, whose steady-state value gives the measurement of $G_{I C}$. Shear fracture testing is considerably more complex and is yet to be standardized [16]. Nonetheless, several different tests have been proposed: End-Notched Flexure (ENF), 4-Point End-Notched Flexure (4ENF) and End-Loaded Split (ELS). Among those, the most commonly used is the ENF, which presents a simple three-point bending setup and reliable data reduction methods. It requires a pre-cracked specimen and a constant measurement of $P, \delta$ and $a$. Since adhesive joints are typically subjected to mixed-mode, few tests are also available to evaluate the mixed-mode strain energy release rate $(G)$, such as the Asymmetric Double-Cantilever Beam (ADCB), the Mixed-Mode Flexure (MMF), the Mixed-Mode Bending (MMB) and the Single-Leg Bending (SLB). The MMB test is the only standardized test available to estimate $G$ of composites, referred in ASTM D6671 [17]. A combination of the DCB and ENF is the basis of the MMB test [18], and allows to change the mixed-mode ratio almost without limit between the pure mode I and pure mode II loading conditions [19]. Hence, it provides a complete understanding of the joints' fracture behaviour under different loadings, known as fracture envelope. The SLB test is simpler than the MMB as it does not require special jigs. However, is more limited with respect to the change of the mixed-mode ratio.

Jung Lee et al. [9] suggested a systematic procedure to evaluate the CZM parameters of an adhesive bond, using SLB tests for the extrapolation of the pure-mode laws, hence simplifying the inverse fitting method. Co-cured specimens were made of steel and unidirectional carbon fibre reinforced material. Measurement of $G$ was carried out from the test data, and the mixed-mode was defined from the classical beam theory. A mixed-mode CZM was applied to reproduce the experiments, including a triangular law shape, the quadratic nominal stress criterion for damage initiation and the linear power law criterion for damage growth. The missing cohesive parameters (stiffness in tension, $K_{\mathrm{nn}}$, stiffness in shear, $K_{\mathrm{ss}}, t_{\mathrm{n}}{ }^{0}$ and $t_{\mathrm{s}}{ }^{0}$ ) were assessed by the design of experiments (DoE) and kriging metamodel (KM) techniques. The authors concluded that the proposed procedure accurately described the fracture behaviour of mixed-mode joints, attaining predictions within $15 \%$ of the experimental data. Moreover, it had the advantage of non-requirement of two separate tests (e.g., DCB for tensile and ENF for shear characterization). Rodrigues et al. [20] determined the fracture envelope of an aluminium adhesive bonded joint in dry and wet conditions, enabling to predict the humidity effect on $G$. After assessing the adhesive moisture absorption capability, DCB and ENF fracture tests were performed for mode I and II, respectively. For the mixed-mode test, an apparatus described in reference [21] was used that allows to test within a range of mode combinations between pure-modes I and II. The dry and wet fracture envelopes showed the ageing effect on the $P_{\mathrm{m}}$ and $P-\delta$ curves. Moreover, the applied methodology enabled obtaining the full fracture envelope with a linear correlation between the pure and mixedmode data points. Nunes and Campilho [22] estimated the fracture envelope of joints bonded with three adhesives with different ductility using the Asymmetric Tapered Double-Cantilever Beam (ATDCB) mixed-mode test. Pure-mode TDCB tests and the Corrected Beam Theory (CBT) were used to assess $G_{\mathrm{IC}}$, and the ENF test together with the Compliance-Based Beam Method (CBBM) served to estimate GIIC. CZM laws were built based on a triangular law and the power law mixedmode growth criterion, and the respective numerical results were compared with the experiments. This enabled to validate the CZM laws and the mixed-mode propagation criterion of each adhesive. Some inconsistencies were detected in the stiffness and $P_{\mathrm{m}}$ of the most ductile adhesive, since the triangular law was not suitable to capture the plasticity inherent to theses adhesives [23]. However, the authors manage to prove that the data reduction method used for the ATDCB specimens is accurate and quick.

The main objective of this work is to verify, by CZM, which is the $\alpha$ value that best suits the energetic crack propagation criterion for CZM modelling, using SLJ and DLJ with aluminium adherends and bonded with three different adhesives. With this purpose, numerical simulations of the SLJ and DLJ are carried out, and $P_{\mathrm{m}}$ is compared with experiments.

\section{EXPERIMENTAL WORK}

\section{Joint materials (fracture tests and lap joints)}

7 he DCB, ENF and SLB adherends, used to build the fracture envelopes of the adhesives, were manufactured from CFRP plates. The composite plates were fabricated using 20 plies with $0.15 \mathrm{~mm}$ thickness each, stacked by handlay-up using unidirectional layers. The SEAL ${ }^{\circledR}$ Texipreg HS 160 RM pre-preg was used in this process. The curing 
process took 1 hour to accomplished and was carried out in a hot-plates press under a temperature and pressure of $130^{\circ} \mathrm{C}$ and 2 bar, respectively. Tab. 1 describes the elastic-orthotropic properties of an CFRP unidirectional layer fabricated under similar conditions [24]. The SLJ and DLJ tested in this work for validation purposes were fabricated from an aluminium alloy sheet metal with reference AW6082-T651. This alloy is produced using a method of artificial ageing, carried at a temperature of $180^{\circ} \mathrm{C}$. This material presents several important features, which were relevant during the material selection, such as the good mechanical properties and the wide field of structural applications in the laminated form. This alloy was characterized in a previous study [25], on bulk specimens, from which the results depicted in Tab. 2 were obtained.

\begin{tabular}{lll}
\hline$E_{\mathrm{x}}=1.09 \mathrm{E}+05 \mathrm{MPa}$ & $v_{\mathrm{xy}}=0.342$ & $G_{\mathrm{xy}}=4315 \mathrm{MPa}$ \\
$E_{\mathrm{y}}=8819 \mathrm{MPa}$ & $v_{\mathrm{xz}}=0.342$ & $G_{\mathrm{xz}}=4315 \mathrm{MPa}$ \\
$E_{\mathrm{z}}=8819 \mathrm{MPa}$ & $v_{\mathrm{yz}}=0.380$ & $G_{\mathrm{yz}}=3200 \mathrm{MPa}$ \\
\hline
\end{tabular}

Table 1: Elastic orthotropic properties of a unidirectional carbon-epoxy ply aligned in the fibres direction ( $x$-direction; $y$ and $z$ are the transverse and through-thickness directions, respectively) [24].

\begin{tabular}{lc}
\hline \multicolumn{1}{c}{ Properties } & Aluminium alloy AW6082 T651 \\
Young's modulus, $E[\mathrm{GPa}]$ & $70.07 \pm 0.83$ \\
Poisson ratio, $v$ & 0.3 \\
Tensile yield stress, $\sigma_{\mathrm{y}}[\mathrm{MPa}]$ & $261.67 \pm 7.65$ \\
Tensile failure stress, $\sigma_{\mathrm{f}}[\mathrm{MPa}]$ & $324.00 \pm 0.16$ \\
Tensile failure strain, $\varepsilon_{\mathrm{f}}[\%]$ & $21.70 \pm 4.24$ \\
Vickers hardness, $[\mathrm{HV}]$ & 100 \\
\hline
\end{tabular}

Table 2: Properties for the aluminium alloy AW6082 T651 [25].

Three adhesives were tested, in order of increasing ductility: Araldite ${ }^{\circledR}$ AV138, Araldite ${ }^{\circledR} 2015$ and Sikaforce ${ }^{\circledR} 7752$. The use of these adhesives allowed testing different materials behaviours. Their tensile mechanical properties, such as the Young's modulus $(E)$, tensile yield stress $\left(\sigma_{\mathrm{y}}\right)$, tensile strength $\left(\sigma_{\mathrm{f}}\right)$ and tensile failure strain $\left(\varepsilon_{\mathrm{f}}\right)$, were defined in previous studies [26$28]$. This was accomplished by tensile testing bulk specimens with a dogbone shape, produced in accordance with the French Standard NF T 76-142, in a servo-hydraulic machine. Example tensile stress-tensile strain curves $(\sigma-\varepsilon)$ are represented in Fig. 1.

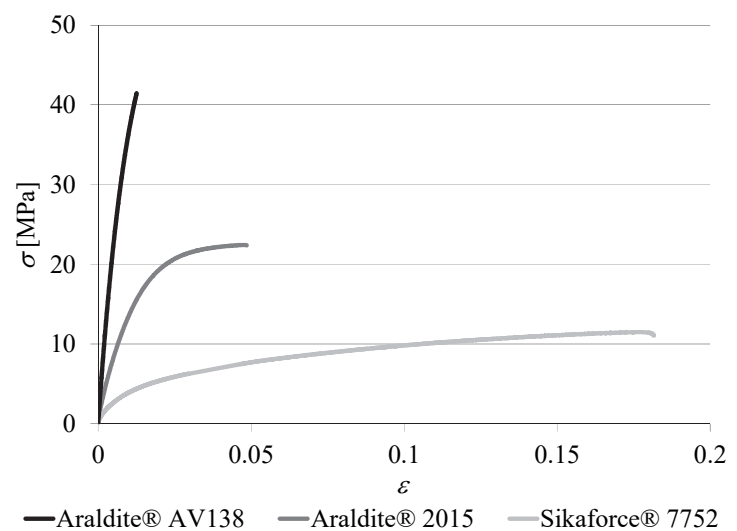

Figure 1: Example of $\sigma-\varepsilon$ curves of the adhesives Araldite ${ }^{\circledR}$ AV138, Araldite ${ }^{\circledR} 2015$ and Sikaforce ${ }^{\circledR} 7752$.

To characterize the adhesives' shear properties, the Thick Adherend Shear Test (TAST) was used in former studies [26-28]. To estimate $G_{\mathrm{IC}}$ and $G_{\mathrm{IIC}}, \mathrm{DCB}$ and ENF tests were performed, respectively. The specimens were fabricated and tested as described in reference [28]. The gathered adhesives' properties are described in Tab. 3. 


\begin{tabular}{|c|c|c|c|}
\hline Property & AV138 & 2015 & 7752 \\
\hline Young's modulus, E [GPa] & $4.89 \pm 0.81$ & $1.85 \pm 0.21$ & $0.49 \pm 0.09$ \\
\hline Poisson's ratio, $v$ & $0.35^{\mathrm{a}}$ & $0.33^{a}$ & $0.30^{a}$ \\
\hline Tensile yield stress, $\sigma_{\mathrm{y}}[\mathrm{MPa}]$ & $36.49 \pm 2.47$ & $12.63 \pm 0.61$ & $3.24 \pm 0.48$ \\
\hline Tensile strength, $\sigma_{\mathrm{f}}[\mathrm{MPa}]$ & $39.45 \pm 3.18$ & $21.63 \pm 1.61$ & $11.48 \pm 0.25$ \\
\hline Tensile failure strain, $\varepsilon_{\mathrm{f}}[\%]$ & $1.21 \pm 0.10$ & $4.77 \pm 0.15$ & $19.18 \pm 1.40$ \\
\hline Shear modulus, $G$ [GPa] & $1.81 \mathrm{~b}$ & $0.70^{b}$ & $0.19^{\mathrm{b}}$ \\
\hline Shear yield stress, $\tau_{\mathrm{y}}[\mathrm{MPa}]$ & $25.1 \pm 0.33$ & $14.6 \pm 1.3$ & $5.16 \pm 1.14$ \\
\hline Shear strength, $\tau_{\mathrm{f}}[\mathrm{MPa}]$ & $30.2 \pm 0.40$ & $17.9 \pm 1.8$ & $10.17 \pm 0.64$ \\
\hline Shear failure strain, $\gamma_{\mathrm{f}}[\%]$ & $7.8 \pm 0.7$ & $43.9 \pm 3.4$ & $54.82 \pm 6.38$ \\
\hline Toughness in tension, $G_{\mathrm{IC}}[\mathrm{N} / \mathrm{mm}]$ & $0.20^{\mathrm{c}}$ & $0.43 \pm 0.02$ & $2.36 \pm 0.17$ \\
\hline Toughness in shear, GIIC $[\mathrm{N} / \mathrm{mm}]$ & $0.38^{\mathrm{c}}$ & $4.70 \pm 0.34$ & $5.41 \pm 0.47$ \\
\hline
\end{tabular}

Table 3: Mechanical and fracture properties of the adhesives Araldite ${ }^{\circledR}$ AV138, Araldite ${ }^{\circledR} 2015$ and Sikaforce ${ }^{\circledR} 7752$ [26-28].

Joint dimensions, fabrication and testing

Fig. 2 illustrates the dimensions and geometry of DCB, ENF and SLB specimens, whereas Fig. 3 represents the geometry and dimensions of the SLJ and DLJ.

a)

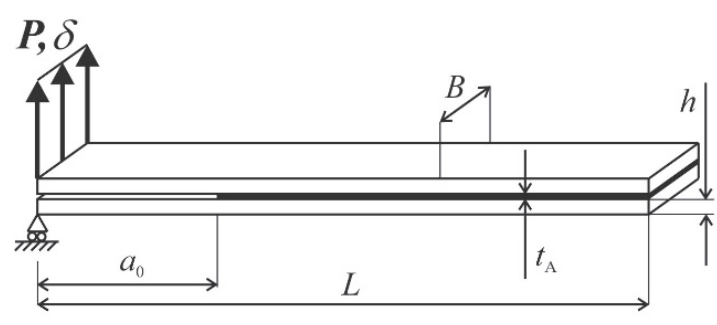

b)

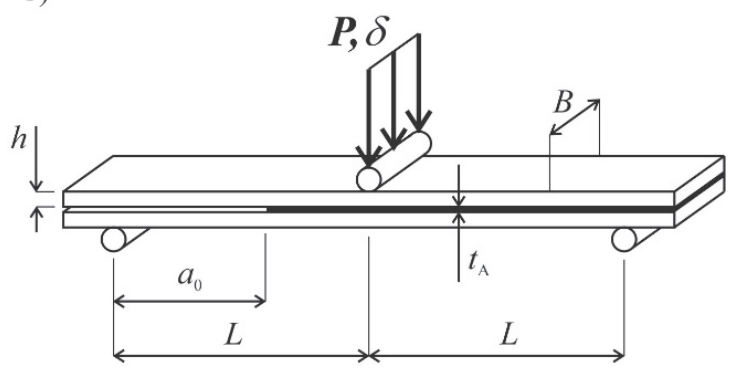

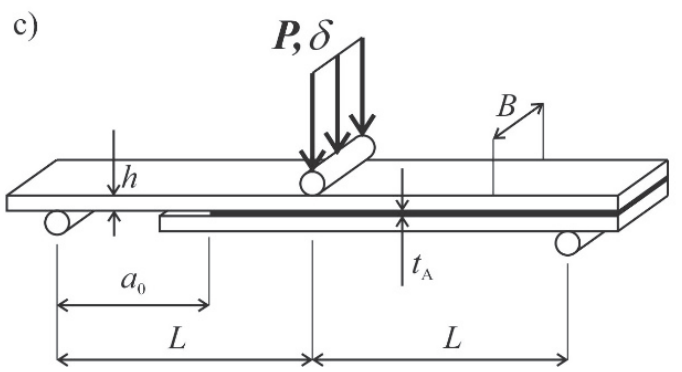

Figure 2: Geometry and dimensions of the DCB (a), ENF (b) and SLB specimens (c).

The specimens' dimensions were as follows next (in mm): total length or mid-span $L=180$ (SLJ and DLJ), $L=140$ (DCB) or $L=100 \mathrm{~mm}$ (ENF and SLB), initial crack length $a_{0} \approx 40 \mathrm{~mm}$ (DCB) or $a_{0} \approx 60 \mathrm{~mm}$ (ENF and SLB), adherends' thickness $b=3$, adhesive thickness $t_{A}=0.2$, joints' width $B=25$ and overlap length $L_{O}=12.5,25,37.5$ and 50 (SLJ and DLJ only). In the present work, the DLJ were fabricated with equal $b$ in the middle and outside adherends, which is not consistent with the 
existence of cross-section balanced adherends. This occurs if the middle adherend has twice $b$ than the outer adherends [29]. However, this was a testing choice that does not compromise the fracture envelopes' validation purpose that this work aims to. Six specimens for each condition were tested for the fracture tests, while five specimens were evaluated for the lap geometries.

(a)

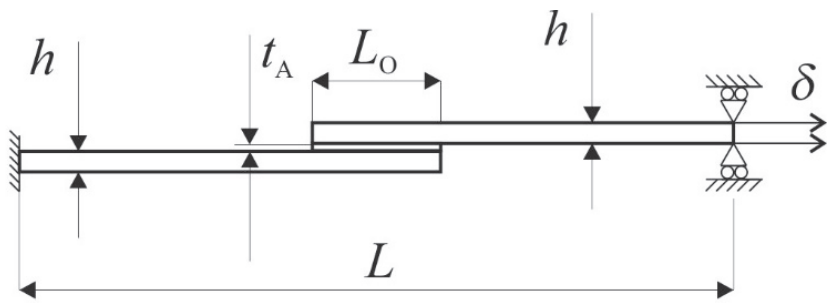

(b)

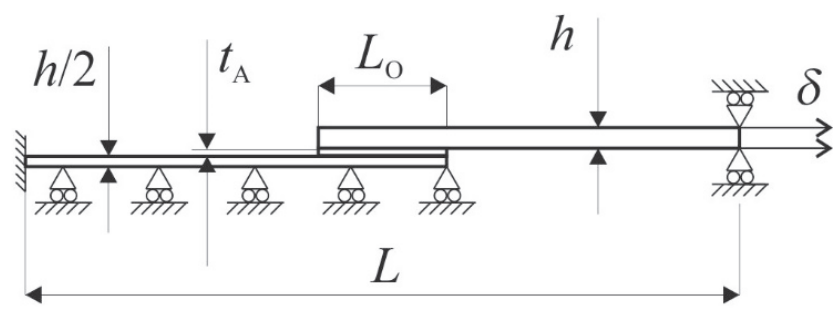

Figure 3: Geometry and dimensions of the single (a) and double-lap joint (b).

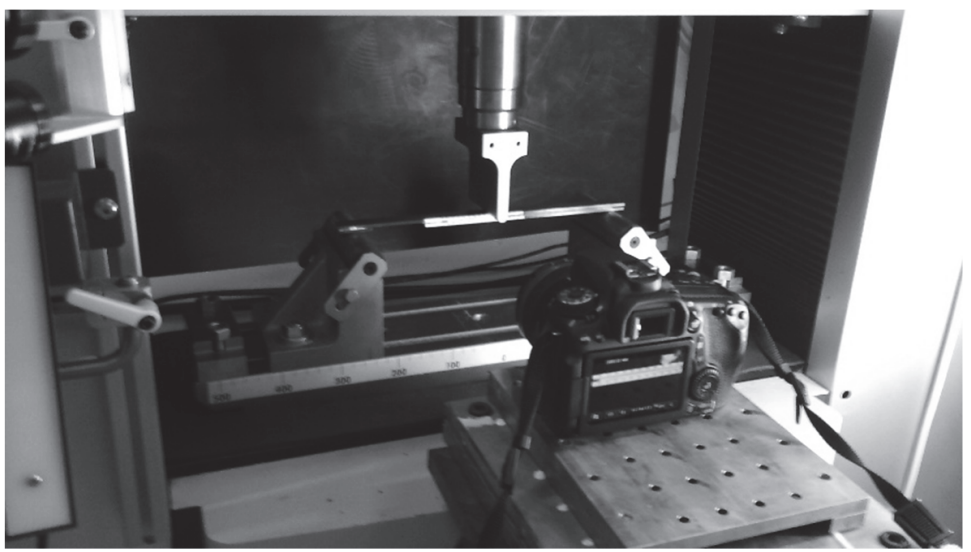

Figure 4: Test setup for the SLB specimens.

For both CFRP and aluminium adherends, the surface preparation prior to bonding was similar: the bonding surfaces were manually abraded using a fine sandpaper to completely remove the shiny surface or aluminium oxide layer, respectively, followed by cleaning and degreasing with acetone. For all tests, and to promote a reliable and dimensionally accurate bonding, the joined parts were placed in a steel mould during the curing process. To guarantee a correct value of $t_{\mathrm{A}}$, for the DCB, ENF and SLB specimens, calibrated metallic spacers were placed between the superior and inferior adherends'. Before their placement, the spacers were coated with demoulding agent to simplify their extraction after curing. These specimens shared the same pre-crack induction method, which consisted in the placement of spacers, in which the crack-tip spacer had a centred sharp razor blade. Nonetheless, to avoid any blunting effects, in each specimen the crack was manually propagated for a length between 1 and $3 \mathrm{~mm}$, and only after the $a_{0}$ measurement took place. In the case of the SLJ and DLJ, $t_{\mathrm{A}}$ was achieved using metallic blocks that were placed in the mould. Regardless the joint type, after pouring the adhesive in one of the adherends, the two adherends were joined and pressured until there was contact with the spacers. This process had to be repeated one more time for the DLJ. Then, the curing process initiated. This took place over one week for all joints. After curing, the spacers or blocks were removed, and the excess adhesive was removed using milling techniques. To allow the measurement of $a$, one side of the DCB, ENF and SLB joints was painted with a brittle white paint and a numbered scale was glued on that side to allow tracking crack propagation. All specimens were tested in an electro-mechanical testing machine Shimadzu AG-X 100 equipped with a $100 \mathrm{kN}$ load cell. The fracture tests were documented by taking pictures with $5 \mathrm{~s}$ intervals, using a digital $18 \mathrm{MPixel}$ camera with no zoom and placed at a focal distance of $100 \mathrm{~mm}$. The DCB, SLJ 
and DLJ specimens were tested in conventional tension, while the ENF and SLB specimens were tested using a three-point bending (3PB) setup. All tests were carried at room temperature and $1 \mathrm{~mm} / \mathrm{min}$ of velocity. The manual $a$ measurement in the DCB, ENF and SLB tests was done by approximating the crack tip to the nearest $1 / 8 \mathrm{of} \mathrm{mm}$ in the scale, which was made possible by the resolution of the images $(0.02 \mathrm{~mm} /$ pixel). The 3PB setup is depicted in Fig. 4 for the case of a SLB specimen.

\section{Fracture toughness estimation}

The Linear Elastic Fracture Mechanics (LEFM) approach is a simple approach to estimate $G$ for strength prediction purposes [30]. However, difficulties arise when dealing with materials (e.g., adhesives) with ductility. On the other hand, typically failure in adhesive bonds takes place under mixed-mode due to the different properties of the joints' components, the applied load and joint architecture, which demands the knowledge of both $G_{\text {IC }}$ and $G_{\text {IIC, }}$ and also the use of mixedmode criteria [22]. In this work, the CBBM data reduction method was selected to estimate $G_{\text {IC }}$ and $G_{\text {IIC }}$ from the DCB and ENF tests, respectively, and $G_{I}$ and $G_{I I}$ from the SLB tests. The CBBM provides the fracture measurements only from the experimental compliance $(C)$ measured during the tests [31]. This method procedure includes an equivalent crack length $\left(a_{\mathrm{eq}}\right)$, which is defined from the $P$ - $\delta$ curve. Moreover, it accounts for the Fracture Process Zone (FPZ), which generates around the crack tip due to the materials' plasticity, otherwise neglected in the analysis when considering the measured value a. For the DCB specimen, GIC is calculated as

$$
G_{\mathrm{IC}}=\frac{6 P^{2}}{B^{2} b}\left(\frac{2 a_{\mathrm{eq}}^{2}}{b^{2} E_{\mathrm{f}}}+\frac{1}{5 G_{\mathrm{xy}}}\right)
$$

where $E_{\mathrm{f}}$ is a corrected flexural modulus to account for stress concentrations at the crack tip and stiffness inconsistency between specimens, and $G_{\mathrm{xy}}$ is the shear modulus of the adherends. Full derivation can be found in the study of Constante et al. [32]. Applied to the ENF test, $G_{\text {IIC }}$ can be obtained by the following expression

$$
G_{\text {IIC }}=\frac{9 P^{2} a_{\mathrm{eq}}^{2}}{16 B^{2} E_{\mathrm{f}} h^{3}} .
$$

A detailed description of the method can be found in reference [31]. The CBBM applied to the SLB specimens, detailed by Fernández et al. [33], is based on the beam theory of Szekrényes and Uj [34]. Application of the Irwin-Kies expression gives the total energy release rate $\left(G_{\mathrm{T}}\right)$ which, after equation splitting according to Szekrényes and Uj [34], provides $G_{\mathrm{I}}$ and $G_{\mathrm{II}}$

$$
G_{\mathrm{I}}=\frac{12 P^{2} a_{\mathrm{eq}}{ }^{2}}{16 B^{2} E_{\mathrm{f}} b^{3}}+\frac{3 P^{2}}{10 G_{\mathrm{xy}} B^{2} b} \text { and } G_{\mathrm{II}}=\frac{9 P^{2} a_{\mathrm{eq}}{ }^{2}}{16 B^{2} E_{\mathrm{f}} b^{3}} \text {. }
$$

\section{NUMERICAL WORK}

\section{Models' construction}

$\mathrm{N}$ umerical simulations were undertaken in Abaqus $^{\circledR}$ to simulate the SLJ and DLJ, in order to validate the experimentally estimated fracture envelopes further in this work. The two-dimensional models included geometrical non-linearities. The models were based on plane-strain elements (CPE4 of Abaqus ${ }^{\circledR}$ ) for the adherends with elastic-plastic continuum formulation and cohesive elements (COH2D4 of Abaqus $\left.{ }^{\circledR}\right)$ for the adhesive layer. In Fig. 5 it is possible to find a typical mesh for the DLJ with $L_{0}=25 \mathrm{~mm}$. It should be stressed that, for all DLJ models, horizontal symmetry was applied to reduce the computational effort. The mesh refinement described next always assured mesh convergence. The elements' size at the adhesive layer's edges was $0.2 \mathrm{~mm} \times 0.2 \mathrm{~mm}$, thus, only a single row of CZM elements was used to populate the adhesive layer thickness. This corresponds to using the continuum CZM approach, in which the CZM laws should reproduce the constitutive behaviour of the full adhesive layer, including the $t_{\mathrm{A}}$-dependent stiffness. For all the models, a total of 8 elements was considered in the adherends through-thickness, whereas between 40 and 160 solid elements were introduced length-wise in the adhesive layer length (between the smallest and largest $L$ ). To speed up the simulations, although without compromising the analysis results, the FE mesh was graded horizontally and vertically (this effect is visible in Fig. 5). All models were fixed at one edge while a vertical restraint and tensile displacement 
were applied at the opposite edge. In the following Section, the triangular CZM formulation, applied in all models and incorporated in $\mathrm{Abaqus}^{\circledR}$, is presented.

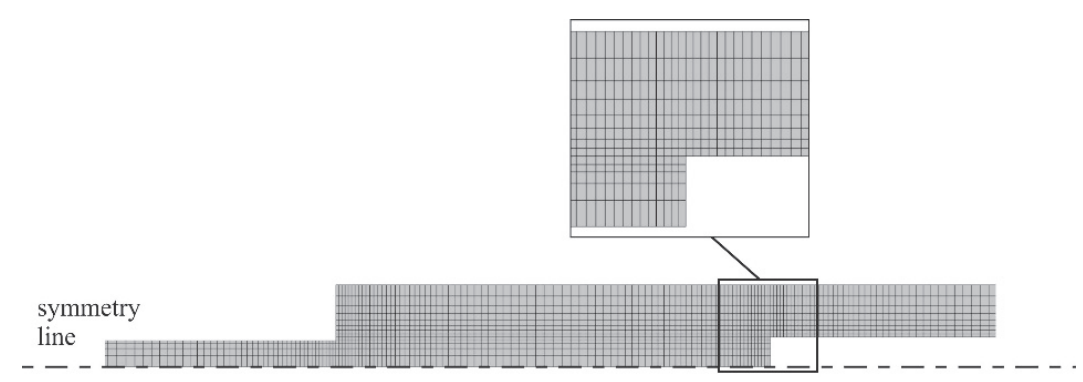

Figure 5: Mesh detail for the $L_{0}=25 \mathrm{~mm}$ double-lap joint (CZM failure analysis).

\section{Mixed-mode triangular model}

CZM are based on a relationship between stresses and relative displacements (in tension or shear) connecting paired nodes of cohesive elements (Fig. 6), to simulate the elastic behaviour up to $t_{\mathrm{n}}{ }^{0}$ in tension or $t_{\mathrm{s}}{ }^{0}$ in shear and subsequent softening, to model the degradation of material properties up to failure. The shape of the softening region can also be adjusted to conform to the behaviour of different materials or interfaces [35]. The areas under the traction-separation laws in tension or shear are equalled to $G_{\text {IC }}$ or $G_{\text {IIC }}$, by the respective order. Under pure loading, damage grows at a specific integration point when stresses are released in the respective damage law. Under a combined loading, stress and energetic criteria are often used to combine tension and shear [36]. The triangular law (Fig. 6) assumes an initial linear elastic behaviour followed by linear degradation. Elasticity is defined by a constitutive matrix $(\mathbf{K})$ containing the stiffness parameters and relating stresses $(\boldsymbol{t})$ and strains $(\boldsymbol{\varepsilon})$ across the interface [37]

$$
\boldsymbol{t}=\left\{\begin{array}{l}
t_{\mathrm{n}} \\
t_{\mathrm{s}}
\end{array}\right\}=\left[\begin{array}{ll}
K_{\mathrm{nn}} & K_{\mathrm{ns}} \\
K_{\mathrm{ns}} & K_{\mathrm{ss}}
\end{array}\right] \cdot\left\{\begin{array}{l}
\varepsilon_{\mathrm{n}} \\
\varepsilon_{\mathrm{s}}
\end{array}\right\}=\mathbf{K} \boldsymbol{\varepsilon}
$$

$t_{\mathrm{n}}$ and $t_{\mathrm{s}}$ are the current tensile and shear tractions, respectively, and $\varepsilon_{\mathrm{n}}$ and $\varepsilon_{\mathrm{s}}$ the corresponding strains. A suitable approximation for thin adhesive layers is provided with $K_{\mathrm{nn}}=E, K_{\mathrm{ss}}=G_{\mathrm{xy}}$ and $K_{\mathrm{ns}}=0$ [25]. Damage initiation can be specified by different criteria. In this work, the quadratic nominal stress criterion was considered for the initiation of damage, already shown to give accurate results [25] and expressed as [37]

$$
\left\{\frac{\left\langle t_{\mathrm{n}}\right\rangle}{t_{\mathrm{n}}^{0}}\right\}^{2}+\left\{\frac{t_{\mathrm{s}}}{t_{\mathrm{s}}^{0}}\right\}^{2}=1 .
$$

\langle\rangle are the Macaulay brackets, emphasizing that a purely compressive stress state does not initiate damage. After the mixedmode cohesive strength is attained $\left(t_{\mathrm{m}}{ }^{0}\right.$ in Fig. 6) by the fulfilment of Eqn. (5), the material stiffness is degraded. Complete separation is normally predicted by a linear power law form of the required energies for failure in the pure modes by considering the power law exponent $\alpha=1$ [37]

$$
\left(\frac{G_{\mathrm{I}}}{G_{\mathrm{IC}}}\right)^{\alpha}+\left(\frac{G_{\mathrm{II}}}{G_{\mathrm{IIC}}}\right)^{\alpha}=1 .
$$

\section{RESULTS}

\section{Fracture envelopes of the adhesives}

7 he present Section aims at estimating the most suitable propagation criterion exponent using the fracture envelope analysis. With this purpose, the pure-mode toughnesses ( $G_{\text {IC }}$ and $\left.G_{\text {IIC }}\right)$ and mixed-mode toughnesses $\left(G_{\mathrm{I}}\right.$ and $\left.G_{\text {III }}\right)$ are first required. 


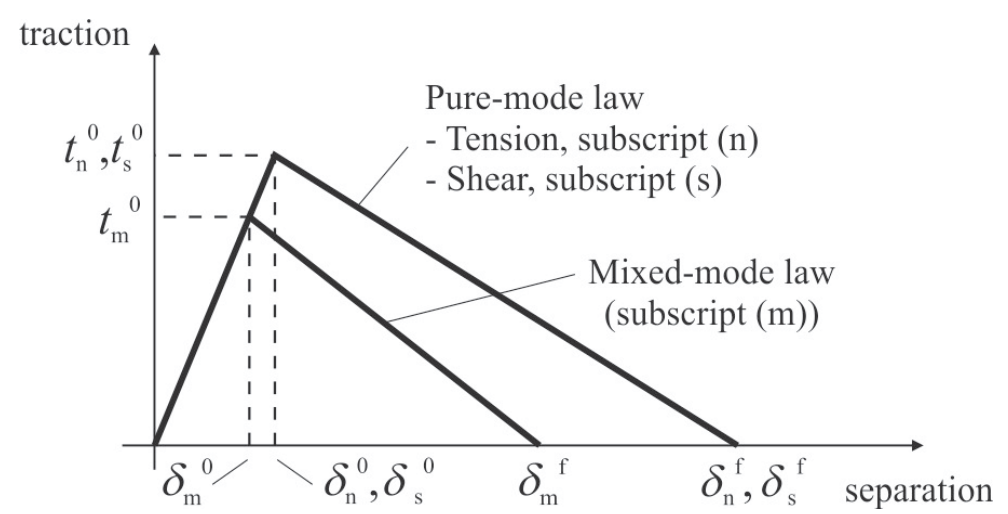

Figure 6: Traction-separation law with linear softening law available in ABAQUS ${ }^{\circledR}$.

\section{$G_{I C}$ and $G_{I I C}$ calculation by the DCB and ENF tests}

$G_{\text {IC }}$ and $G_{\text {IIC }}$ were calculated by the CBBM data reduction method using the DCB and ENF tests, respectively. The $P$ - $\delta$ curves obtained for both tests were all consistent between specimens joined with each adhesive. Regarding damage growth of the specimens bonded with Araldite ${ }^{\circledR}$ AV138, all attained a brittle failure, which grows abruptly throughout the bondline. On the other hand, both Araldite ${ }^{\circledR} 2015$ and Sikaforce ${ }^{\circledR} 7752$ suffered a gradual failure accompanied by a reduction of $P$. The R-curves depicted the expected steady-state crack growth for both loading modes, which represent the $G_{\text {IC }}$ and $G_{\text {IIC }}$ values [38]. Nevertheless, crack propagation presented few oscillations mainly owing to small fabrication defects and imperfections, adhesive mixing variations and crack arrest phenomena [39]. In the ENF test, GIIC can be measured up to the crack reaching the proximity of the loading cylinder, because at this zone the almost pure-shear stress state is cancelled due to the compression effect. Tab. 4 presents the average $G_{\text {IC }}$ and $G_{\text {IIC }}$ and respective deviation of all specimens bonded with the three adhesives. The highest standard deviation, normalized over the average fracture toughness, was $10.4 \%$ for the Araldite ${ }^{\circledR}$ AV138 ( $G_{\text {IIC }}$ ), depicting the repeatability of the experimental tests. Comparing these values with the ones presented in Tab. 3, the following deviations were found for $G_{\mathrm{IC}}:-30.0$, +25.6 and $+60.4 \%$ for the adhesives Araldite ${ }^{\circledR}$ AV138, Araldite ${ }^{\circledR} 2015$ and the Sikaforce ${ }^{\circledR} 7752$, respectively. Regarding the deviations for $G_{\text {IIC, }}$ the values were: $-7.4,-37.1$

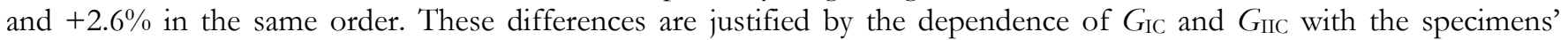
geometry, more specifically with $h$ and $t_{\mathrm{A}}$, given that these parameters influence FPZ' size in the vicinity of the crack tip $[40]$.

\begin{tabular}{llll}
\hline Adhesive & Araldite $^{\circledR}$ AV138 & Araldite $^{\circledR} 2015$ & Sikaforce $^{\circledR} 7752$ \\
\hline Fracture toughness & GIC & $G_{\text {IIC }}$ & $G_{\text {IC }}$ \\
Average & 0.140 & 0.352 & 0.540 \\
Deviation & 0.012 & 0.037 & 0.041 \\
\hline
\end{tabular}

Table 4: Average values of $G_{I C}$ and $G_{\text {IIC }}$ and respective deviation [in N/mm] obtained by the DCB and ENF tests, respectively.

\section{$G_{I}$ and $G_{I I}$ calculation by the SLB tests}

The $P-\delta$ curves of the SLB specimens bonded with the Araldite ${ }^{\circledR}$ AV138 are depicted in Fig. 7 as an example of the repeatability between specimens of each adhesive. Generally, a good reproducibility was found between specimens bonded with same adhesive regarding the elastic stiffness (up to $P_{\mathrm{m}}$ ). The only exception occurs with an Araldite ${ }^{\circledR}$ AV138 specimen due to a higher $a_{0}$ value, nonetheless, this does not affect the measurements. Crack growth was usually stable, apart from few Araldite ${ }^{\circledR}$ AV138 specimens in which, after $P_{\mathrm{m}}$ is attained, the load falls abruptly due to crack growth instability associated to the brittleness of this adhesive. This can also be indicative that this particular adhesive is affected by the presence of small defects that trigger this behaviour [32]. The crack growth behaviour was also similar between specimens bonded with the same adhesive. On the other hand, the ductility of the Araldite ${ }^{\circledR} 2015$ and the Sikaforce ${ }^{\circledR} 7752$ led to a softening near $P_{\mathrm{m}}$. Fig. 8 shows example tensile (a) and shear (b) experimental R-curves for an SLB specimen with the adhesive Araldite ${ }^{\circledR}$ AV138. One may notice that crack propagates at a fairly accurate steady-state value of $G_{\text {I }}$ or $G_{\text {II }}$ (for $\left.130 \leq a_{\mathrm{eq}} \leq 180\right)$. This constant crack growth region was the one considered to estimate both $G_{\mathrm{I}}$ or $G_{\mathrm{II}}$ values. In fact, when the adhesives' FPZ spreads to the loading cylinder, the toughness artificially increases owing to the compression effects of the applied load. The R-curves for the joints bonded with the Araldite ${ }^{\circledR} 2015$, compared to the ones showed in Fig. 8, 
presented a reduction of the constant $G_{\mathrm{I}}$ and $G_{\text {II }}$ extent because of the inherent ductility of this adhesive. On the other hand, the Sikaforce ${ }^{\circledR} 7752$ R-curves showed a minor increasing trend of $G_{I}$ and $G_{I I}$ with $a$ in line for the large dimensions of the FPZ.

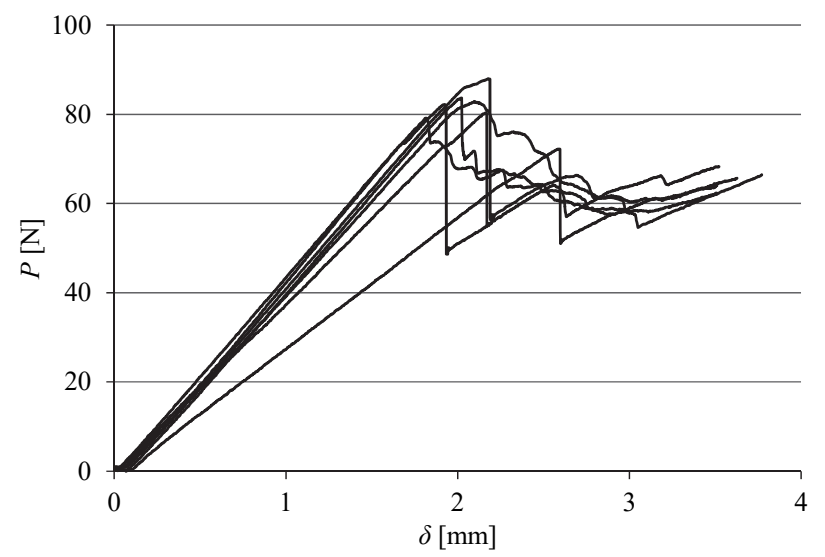

Figure 7: $P$ - $\delta$ curves obtained for the SLB specimens with the adhesive Araldite ${ }^{\circledR}$ AV138.

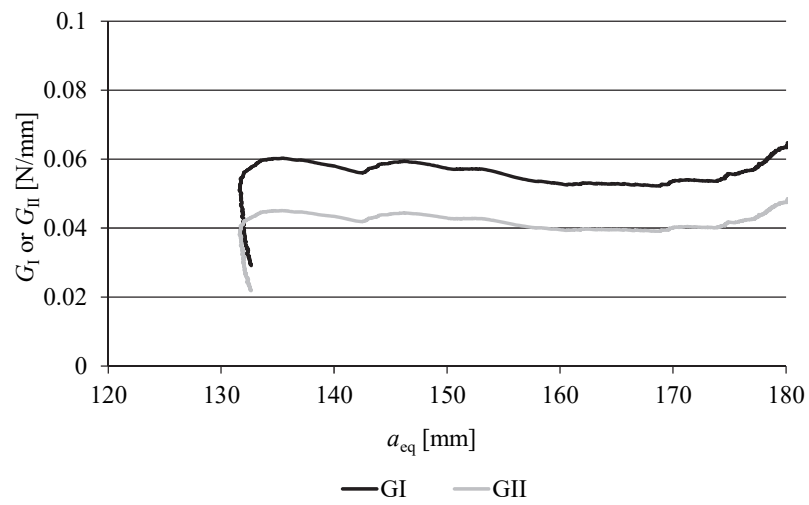

Fig. 8: Example of tensile (a) and shear (b) experimental R-curves for an SLB specimen with the adhesive Araldite ${ }^{\circledR}$ AV138.

\section{Fracture envelope}

The fracture envelopes of the three tested adhesives depicted in Fig. 9 were constructed from the mixed-mode results of the SLB tests and also the pure-mode $G_{I C}$ and $G_{\text {IIC }}$ values. In all cases, the CBBM data reduction method was used. Four theoretical fracture envelopes are presented, by applying an energetic crack propagation criterion of the type of Eqn. (6) with the exponents $\alpha=1 / 2,1,3 / 2$ and 2 . This will enable framing the behaviour of each adhesive in the most appropriate criterion. Regarding the Araldite ${ }^{\circledR}$ AV138, a small relative standard deviation of the experimental data was attained, i.e., 5.2 and $5.9 \%$ for $G_{\mathrm{I}}$ and $G_{\mathrm{III}}$, respectively. Oppositely, the other two adhesives presented a higher scatter in the experimental outcomes, even though this was still satisfactory. Actually, the deviation found for $G_{I}$ and $G_{\text {II }}$ was by $9.4 \%$ and $9.2 \%$, respectively, for the Araldite ${ }^{\circledR} 2015$, and $3.7 \%$ and $3.6 \%$ for the Sikaforce ${ }^{\circledR} 7752$, in the same order. The energetic propagation criterion with $\alpha=1 / 2$ provides a good agreement to the behaviour of the Araldite ${ }^{\circledR}$ AV138. The same exponent is also the best solution for the Araldite ${ }^{\circledR} 2015$, even though the correlation is not as obvious as for the Araldite ${ }^{\circledR}$ AV138.

On the other hand, the Sikaforce ${ }^{\circledR} 7752$ presents a noticeably different mixed-mode behaviour compared to that of the other adhesives, in such a way that the mixed-mode energies during propagation largely exceed the linearity between the corresponding pure-mode values. In fact, for this adhesive, the best propagation criterion exponent to be used in mixedmode simulations is $\alpha=2$.

\section{Validation with lap geometries}

This Section aims at validating the estimated mixed-mode crack propagation criteria defined for each adhesive. With this purpose, initially the experimental $P_{\mathrm{m}}$ results for the SLJ and DLJ are presented and discussed. Following, $P_{\mathrm{m}}$ prediction takes place for all tested conditions, and the relevant conclusions are taken. 


\section{Experimental strength}

Fig. 10 provides the experimental $P_{\mathrm{m}}$ of the SLJ (a) and DLJ (b) bonded with the three adhesives as a function of $L_{0}$. For both SLJ and DLJ, the behaviour highly differs depending on the adhesive. Here, the values of $E$ and $G_{x y}$ have a major influence on the stress distributions and, thus, on $P_{\mathrm{m}}$. Actually, Adams [4] proved that a smaller adhesive stiffness is linked to more uniform stresses along $L_{0}$. In view of this, the joints with the Araldite ${ }^{\circledR}$ AV138 should have higher peak stresses. It is also known that $\sigma_{\mathrm{y}}$ and $\tau_{\mathrm{xy}}$ peak stresses in the overlap increase with $L_{\mathrm{o}}$ [41], turning $P_{\mathrm{m}}$ in joints with large $L_{0}$ highly dependent on the plasticization ability while, in joints with short $L_{0}, P_{\mathrm{m}}$ is mostly dependent on the adhesive strength. Moreover, joints with a brittle adhesive should fail when the adhesive's strength is attained. Joints with ductile adhesives undergo plasticity at the bond edges at the same time that the inner bond becomes increasingly loaded, which is usually linked to an increase in $P_{\mathrm{m}}[42]$.
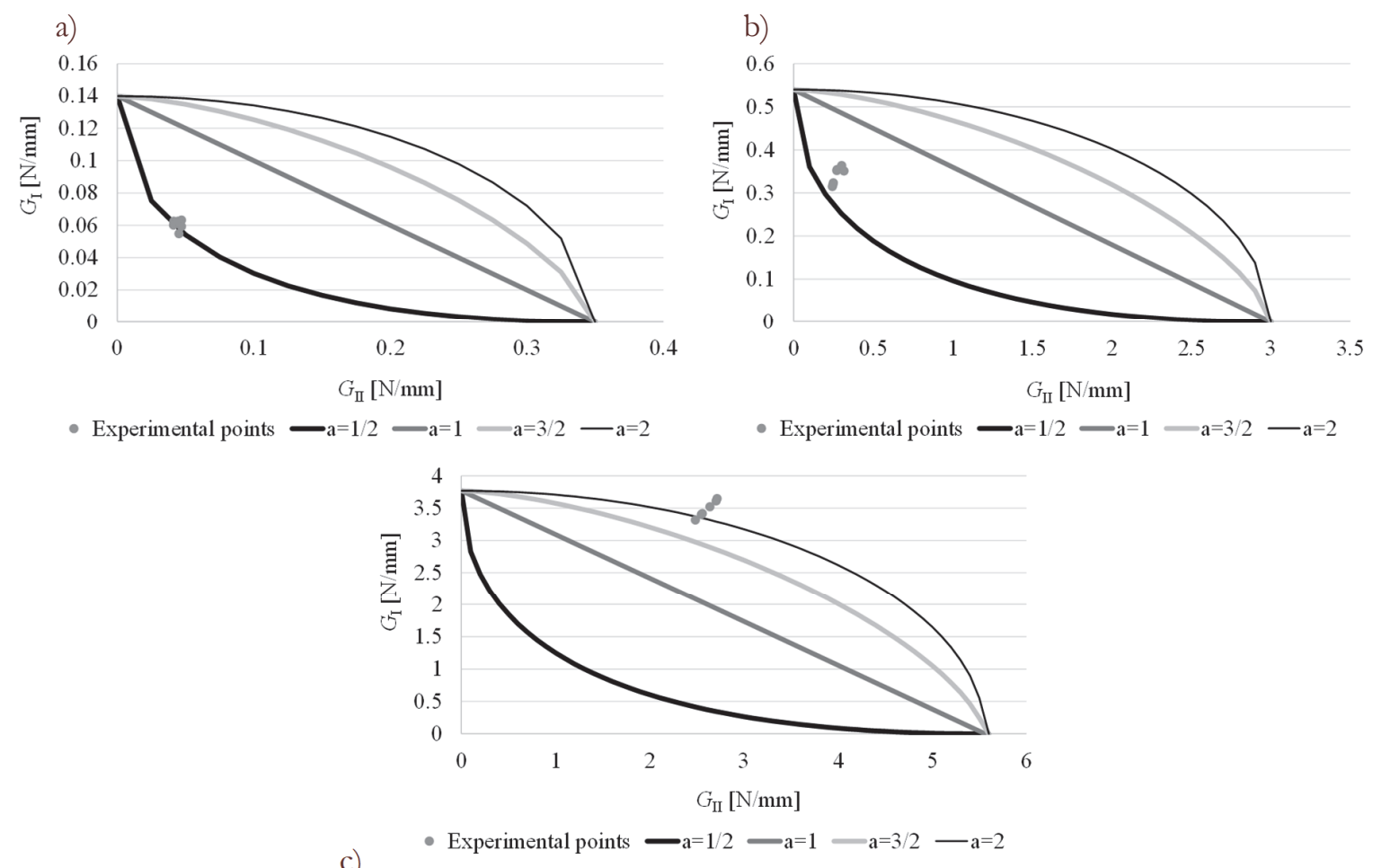

c)

Figure 9: Idealised fracture envelopes and experimental $G_{I} / G_{I I}$ data points for each of the adhesives: (a) Araldite ${ }^{\circledR}$ AV138, (b) Araldite ${ }^{\circledR}$ 2015 and (c) Sikaforce ${ }^{\circledR} 7752$.

In view of this, the SLJ results of Fig. 10 (a) reveal that the strong and brittle Araldite ${ }^{\circledR}$ AV138 shows higher $P_{\mathrm{m}}$ for $L_{\mathrm{O}}=12.5$ $\mathrm{mm}$ compared to the less strong but ductile Araldite ${ }^{\circledR} 2015$ (difference of 2.5\%). The increase of peak stresses for higher $L_{0}$ [41] inhibits large $P_{\mathrm{m}}$ improvements with $L_{0}$ for the joints with the Araldite ${ }^{\circledR}$ AV138. As a result, the Araldite 2015 progressively performs better than the Araldite ${ }^{\circledR}$ AV138 by increasing $L_{0}$, due to its ductility. The difference between these two adhesives attains $62.5 \%$ for $L_{0}=50 \mathrm{~mm}$. The Sikaforce ${ }^{\circledR} 7752$ is the less strong adhesive but, on the other hand, it is highly ductile, enough for the adhesive layer to fracture under generalized plasticization conditions up to large Lo. Thus, for small $L_{0}$ this adhesive is not competitive due to failure being governed by the strength rather than the toughness. The $P_{\mathrm{m}}$ offset, for $L_{\mathrm{O}}=12.5 \mathrm{~mm}$, is $33.1 \%$ to the Araldite ${ }^{\circledR} \mathrm{AV} 138$ and $31.4 \%$ to the Araldite ${ }^{\circledR} 2015$. On the other hand, due to its marked ductility, $P_{\mathrm{m}}$ increases nearly linearly with $L_{0}$. For $L_{0}=50 \mathrm{~mm}, P_{\mathrm{m}}$ is proximal to that of the Araldite ${ }^{\circledR} 2015$ (difference of only $5.3 \%$ ), while it is higher than the Araldite ${ }^{\circledR}$ AV138 by $54.0 \%$.

For the DLJ (Fig. $10 \mathrm{~b}$ ) and $L_{0}=12.5 \mathrm{~mm}$, the Araldite ${ }^{\circledR}$ AV138 is also close to the Araldite ${ }^{\circledR} 2015$ ( $P_{\mathrm{m}}$ of the Araldite $^{\circledR}$ AV138 only excels by $1.0 \%$ ). However, the $P_{\mathrm{m}}$ vs. $L_{0}$ plots gradually deviate with the increase of $L_{0}$ due to the less marked $P_{\mathrm{m}}$ increase for the Araldite ${ }^{\circledR}$ AV138 (the approximate differences attained 30\%). Apart from this, the plastic deformation initiated at $P \approx 16 \mathrm{kN}$ in the inner adherend, while tensile net failure of the same adherend occurred at $P \approx 24 \mathrm{kN}$. This occurrence was responsible for the disruption of the $P_{\mathrm{m}}$ vs. $L_{0}$ curves of both the Araldite ${ }^{\circledR} 2015$ and Sikaforce ${ }^{\circledR} 7752$, and it also affected the behaviour of the joints bonded with the Araldite ${ }^{\circledR}$ AV138, even for small adherend plasticization. The 
joints bonded with the Araldite ${ }^{\circledR} 2015$ suffered significant plasticization for $L_{0}=25 \mathrm{~mm}$, although failing cohesively in the adhesive layer, while tensile adherend failure was encountered for $L_{\mathrm{O}}>25 \mathrm{~mm}$. Thus, the $P_{\mathrm{m}}$ vs. $L_{0}$ curve presents a steadystate $P_{\mathrm{m}}$ for $L_{\mathrm{O}} \geq 25 \mathrm{~mm}$. Using the Sikaforce ${ }^{\circledR} 7752$ led to a diminished $P_{\mathrm{m}}$ for $L_{\mathrm{O}}=12.5 \mathrm{~mm}$ because of the adhesive strengths. Despite this fact, due to its toughness, this adhesive has an improved performance for bigger $P_{\mathrm{m}}$. This improvement is nearly linear up to $L_{\mathrm{O}}=37.5 \mathrm{~mm}$. Bigger $L_{0}$ promote the inner adherend's failure and limit $P_{\mathrm{m}}$ to $\approx 24 \mathrm{kN}$.
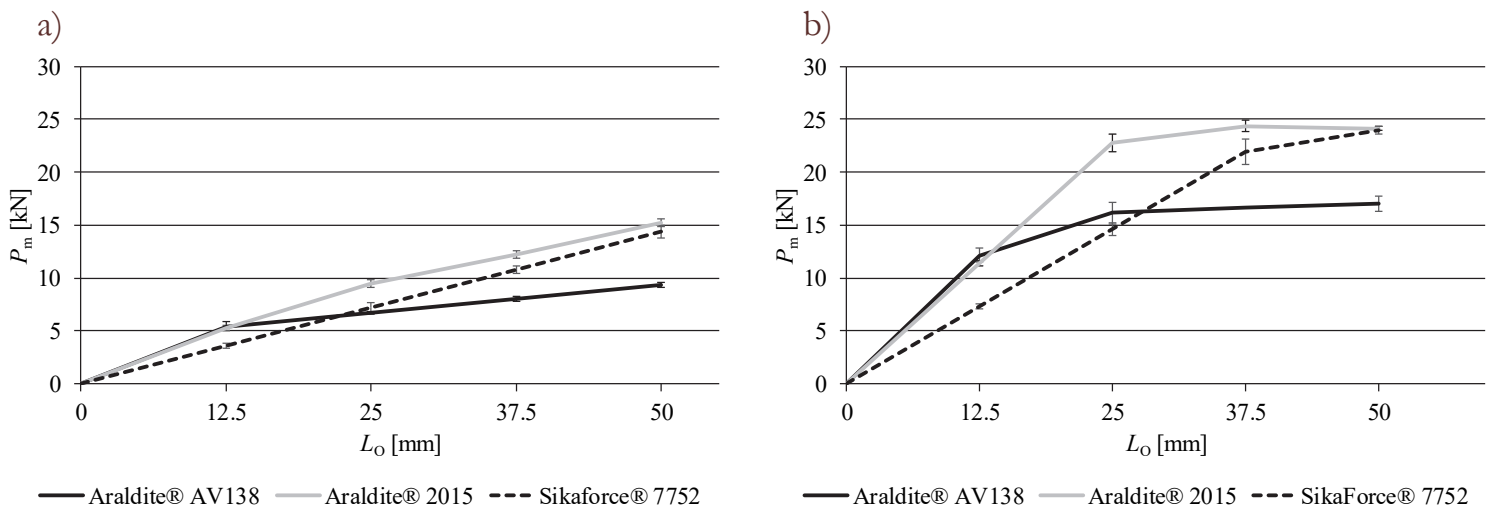

Figure 10: Experimental $P_{\mathrm{m}}$ values for the SLJ (a) and DLJ (b) bonded with the three adhesives.

\section{Mixed-mode crack propagation criterion validation}

Fig. 11, and Fig. 12, Fig. 13 show the comparison between the $P_{\mathrm{m}}$ values obtained experimentally with the numerical ones for the different $L_{0}$ and $\alpha$ exponents for the SLJ (a) and DLJ (b) bonded with the Araldite ${ }^{\circledR}$ AV138, Araldite ${ }^{\circledR} 2015$ and Sikaforce ${ }^{\circledR} 7752$, respectively. The pure-mode CZM laws of the adhesives were inserted by the definition of $E, G_{\mathrm{xy}}, t_{\mathrm{n}}{ }^{0}, t_{\mathrm{s}}{ }^{0}$, $G_{\text {IC }}$ and $G_{\text {IIC. }}$ These properties were all taken from the data of Tab. 3, with the particularity that $t_{\mathrm{n}}{ }^{0}$ and $t_{\mathrm{s}}{ }^{0}$ are made equal to $\sigma_{\mathrm{f}}$ and $\tau_{\mathrm{f}}$, respectively [26]. The mixed-mode behaviour is defined from the damage initiation criterion (quadratic stress criterion in this case) and damage growth criterion (power law criterion with the user specification of $\alpha$ ).

For the Araldite ${ }^{\circledR}$ AV138 (Fig. 11), and first considering the SLJ, it can be concluded that the experimental $P_{\mathrm{m}}$ points are closest to the numerical predictions with $\alpha=0.5$. As a result, the experimentally obtained fracture envelope is considered valid, since the experimental and the numerical behaviours were in agreement. The largest percentile deviation between these two sets of values was $-4.94 \%\left(L_{0}=12.5 \mathrm{~mm}\right)$. The highest offset was found for $\alpha=2$, with a maximum deviation of $+36.43 \%$ ( $\left.L_{0}=50 \mathrm{~mm}\right)$. Identically, for the DLJ, the numerical curve relating to $\alpha=0.5$ also proved to be the most accurate, and showed a maximum deviation to the experiments of $-5.00 \%\left(L_{\mathrm{O}}=50 \mathrm{~mm}\right)$. It should be mentioned that, for $L_{\mathrm{O}} \geq 25$ $\mathrm{mm}, P_{\mathrm{m}}$ becomes affected by adherends' plasticization for $\alpha=1,1.5$ and 2 , which prevents predicted $P_{\mathrm{m}}$ with a larger offset than that depicted in the figure. As a result of this discussion, the formerly obtained experimental envelope is validated. The results for the Araldite ${ }^{\circledR} 2015$ (Fig. 12) showed that, for the SLJ, the most suitable $\alpha$ is also 0.5, as predicted in the formerly discussed fracture tests, and that it gives a good representation of the experimental behaviour. The predicted $P_{\mathrm{m}}$ are always above the experiments, with relative differences that range between $+4.90 \%\left(L_{\mathrm{o}}=37.5 \mathrm{~mm}\right)$ to $+14.39\left(L_{\mathrm{O}}=12.5 \mathrm{~mm}\right)$. This enables validating the mixed-mode criterion for crack propagation. On the other hand, the other tested $\alpha$ revealed higher deviations by increasing $\alpha$ up to a value of 2 . Here, the maximum offset was $+40.74 \%$, for $L_{0}=50 \mathrm{~mm}$.

An identical agreement was also found for the DLJ. However, for $L_{0} \geq 25 \mathrm{~mm}$, the joints' failure becomes governed by the net adherends' fracture, and the $P_{\mathrm{m}}$ results between different $\alpha$ become insignificant. Also because of this, the deviations are generally not relevant. For $\alpha=0.5$, the maximum error was $-3.55 \%$ for $L_{0}=50 \mathrm{~mm}$. Between all $\alpha$, the maximum error was $+5.46 \%\left(\alpha=2\right.$ and $\left.L_{0}=25 \mathrm{~mm}\right)$. As a result of this discussion, the formerly obtained experimental envelope is validated. In opposition to these two adhesives, for the Sikaforce ${ }^{\circledR} 7752, \alpha=2$ is the best solution. However, it was found that, for the joints bonded with the Sikaforce ${ }^{\circledR} 7752$, the change of $\alpha$ does not result in large $P_{\mathrm{m}}$ changes. Actually, for the SLJ, the offset between the tests and predictions steadily increased with $L_{0}$, up to a maximum of $-16.58,-15.84,-15.74$, and $-15.71 \%$ for $L_{\mathrm{O}}=50 \mathrm{~mm}$ and increasing $\alpha$ from $0.5 \mathrm{up}$ to 2 . The DLJ are affected by the adherends' failure at $L_{\mathrm{O}}=50 \mathrm{~mm}$. The maximum errors were obtained for $L_{\mathrm{O}}=37.5 \mathrm{~mm}$ for all $\alpha$, and took values of $-15.50,-15.40,-15.39$, and $-15.39 \%$ by increasing order of $\alpha$. On the other hand, for the joints bonded with the other two adhesives, the modification of $\alpha$ revealed a great influence on $P_{\mathrm{m}}$. A more detailed study showed that the influence of this parameter on $P_{\mathrm{m}}$ gradually diminishes with the adhesives' 
ductility. On the other hand, the slight deviations between the experiments and simulations were found to due to using a triangular CZM to model a highly ductile adhesive [35].

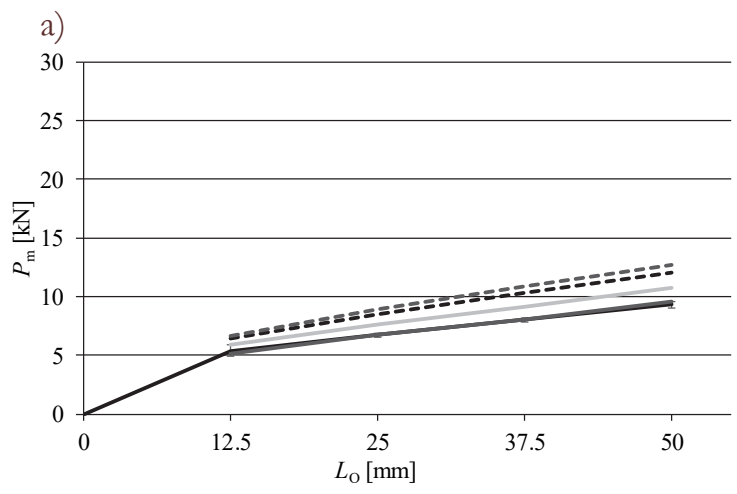

- AV138 $\operatorname{Exp}-0.5-1---1.5---2$

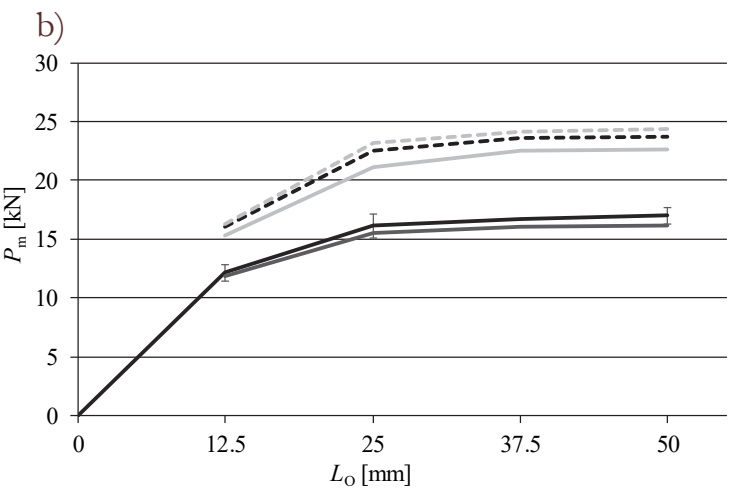

$-\mathrm{AV} 138 \mathrm{Exp}-0.5-1---1.5---2$

Figure 11: Comparison between experimental and numerical $P_{m}$ values for the SLJ (a) and DLJ (b) bonded with the Araldite ${ }^{\circledR}$ AV138, considering different $\alpha$.
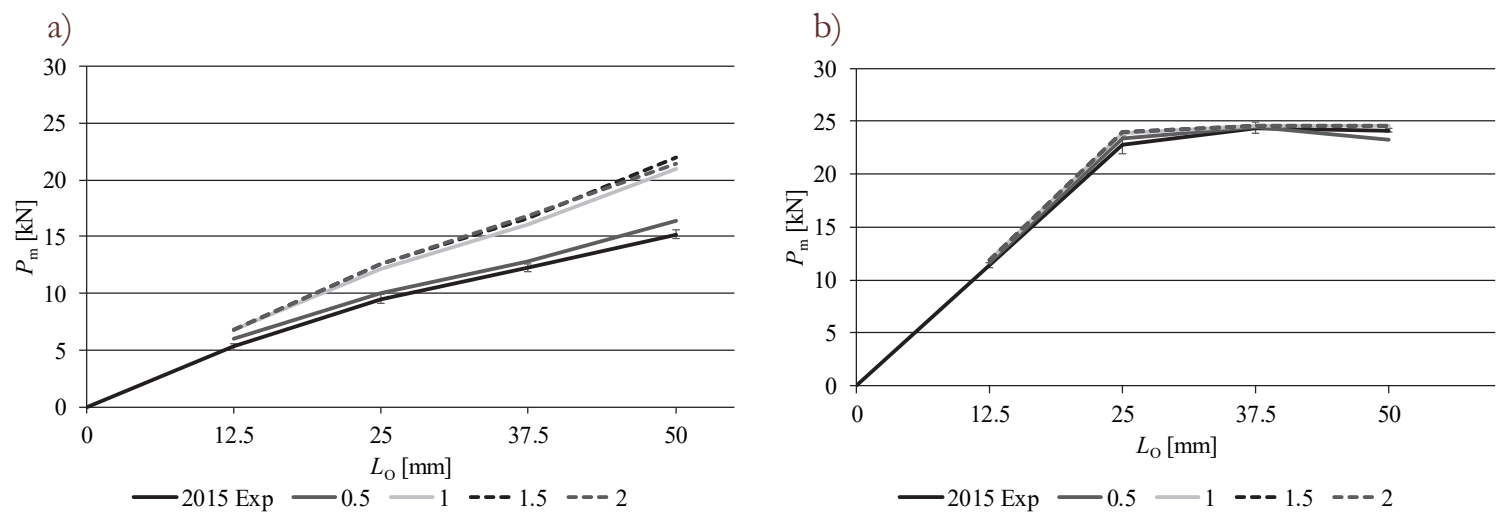

Figure 12: Comparison between experimental and numerical $P_{m}$ values for the SLJ (a) and DLJ (b) bonded with the Araldite ${ }^{\circledR}$ 2015, considering different $\alpha$.
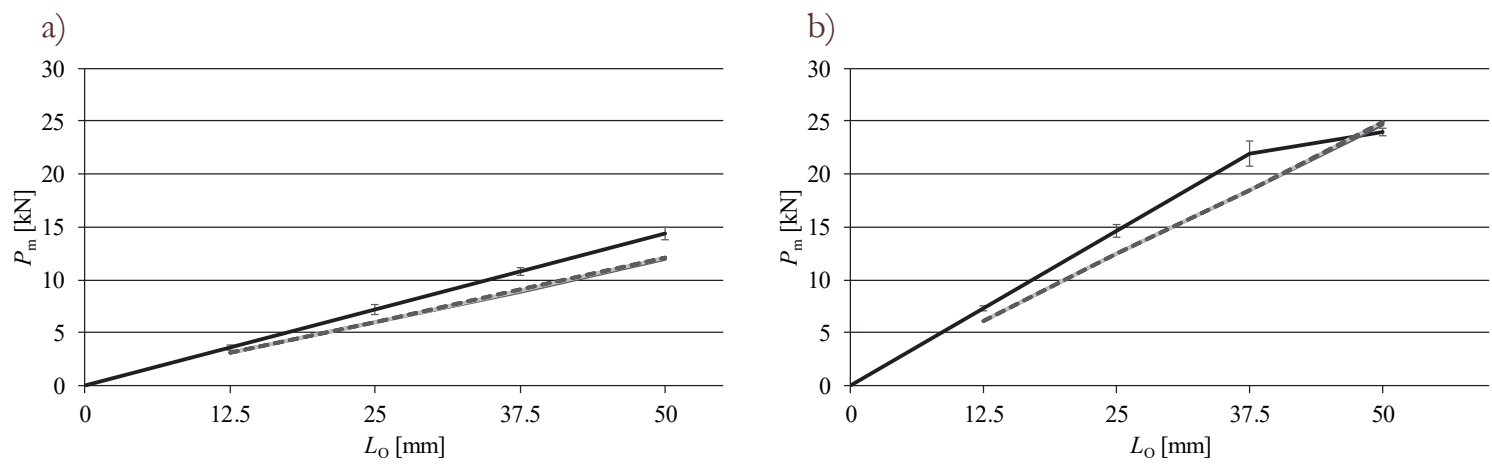

-7752 $\operatorname{Exp}-0.5-1 \quad---1.5 \quad---2$

—7752 $\operatorname{Exp}-0.5-1 \quad---1.5 \quad---2$

Figure 13: Comparison between experimental and numerical $P_{m}$ values for the SLJ (a) and DLJ (b) bonded with the Sikaforce ${ }^{\circledR} 7752$, considering different $\alpha$. 


\section{CONCLUSIONS}

$\mathrm{T}$

he proposed work aimed at experimentally defining the most suitable $\alpha$ parameter for the mixed-mode crack propagation prediction of three structural adhesives. With this purpose, pure and mixed-mode fracture tests were undertaken that enabled building the fracture envelopes of the three adhesives. Brittle crack propagation issues were detected in some specimens bonded with the Araldite ${ }^{\circledR}$ AV138, due to its brittleness. On the other hand, the Araldite ${ }^{\circledR}$ 2015 and Sikaforce ${ }^{\circledR} 7752$ revealed a ductile failure, which, together with the $G_{I} / G_{\text {II }}$ and $G_{\text {IC }} / G_{\text {IIC }}$ values obtained, confirmed their expected ductile behaviour. The $R$-curves enabled estimating the data points that were on the basis of the built fracture envelopes. The experimental data points revealed a different mixed-mode behaviour, with $\alpha=0.5$ giving a close match for the Araldite ${ }^{\circledR}$ AV138 and Araldite ${ }^{\circledR}$ 2015, while $\alpha=2$ closely represented the Sikaforce ${ }^{\circledR} 7752$. Validation of this data was undertaken with SLJ and DLJ. However, a previous experimental data discussion was presented, enabling to realize that the lap-joints' behaviour is highly dependent on the adhesive type and $L_{0}$. More particularly, it was found that strong yet brittle adhesive behave well for short $L_{0}$, while this is not true for large $L_{0}$. For these geometries, less strong but ductile adhesives take advantage, on view of the ability to endure loads after damage onset takes place. After this analysis, numerical simulations of the SLJ and DLJ were made with different $\alpha$, and $P_{\mathrm{m}}$ was compared with experiments. For the Araldite ${ }^{\circledR}$ AV138 and Araldite ${ }^{\circledR}$ 2015, the energetic criterion resulting from the experimental work provided matching numerical results and, thus, the fracture envelopes were validated. For these two adhesives and the chosen $\alpha$, the deviations were mostly under 10\%. The Sikaforce ${ }^{\circledR} 7752$ results were slightly offset due to CZM law shape issues. In the end, this work made possible, by CZM, to estimate the most suitable $\alpha$ parameter to use in crack propagation of adhesive joints under mixed-mode conditions.

\section{REFERENCES}

[1] da Silva, J.F.M.G., Öchsner, A., Adams, R.D. Handbook of Adhesion Technology. Heidelberg: Springer; 2011.

[2] Loureiro, A.L., da Silva, L.F.M., Sato, C., Figueiredo, M.A.V. (2010). Comparison of the Mechanical Behaviour Between Stiff and Flexible Adhesive Joints for the Automotive Industry. J Adhesion. 86, pp. 765-87.

DOI: $10.1080 / 00218464.2010 .482440$.

[3] Petrie, E.W. (1999). Handbook of adhesives and sealants. 2nd ed ed. New York: McGraw-Hill.

[4] Adams, R.D. (2005). Adhesive bonding: science, technology and applications. Cambridge: Woodhead Publishing Limited.

[5] Kinloch, A.J. (1987). Adhesion and Adhesives: Science and Technology. Heidelberg: Springer.

[6] He, X. (2011). A review of finite element analysis of adhesively bonded joints. Int J Adhes Adhes. 31, pp. 248-64. DOI: 10.1016/j.ijadhadh.2011.01.006.

[7] Barenblatt, G.I. (1959). The formation of equilibrium cracks during brittle fracture. General ideas and hypotheses. Axially-symmetric cracks. Journal of Applied Mathematics and Mechanics. 23, pp. 622-36.

DOI: 10.1016/0021-8928(59)90157-1.

[8] Dugdale, D.S. (1960). Yielding of steel sheets containing slits. J Mech Phys Solids. 8, pp. 100-4. DOI: 10.1016/0022-5096(60)90013-2.

[9] Jung Lee, M., Min Cho, T., Seock Kim, W., Chai Lee, B., Ju Lee, J. (2010). Determination of cohesive parameters for a mixed-mode cohesive zone model. International Journal of Adhesion and Adhesives. 30, pp. 322-8. DOI: 10.1016/j.ijadhadh.2009.10.005.

[10] Andersson, T., Stigh, U. (2004). The stress-elongation relation for an adhesive layer loaded in peel using equilibrium of energetic forces. Int J Solids Struct. 41, pp. 413-34. DOI: 10.1016/j.ijsolstr.2003.09.039.

[11] Pandya, K.C., Williams, J.G. (2000). Measurement of cohesive zone parameters in tough polyethylene. Polymer Engineering \& Science. 40, pp. 1765-76. DOI: 10.1002/pen.11308.

[12] Banea, M.D., da Silva, L.F.M., Campilho, R.D.S.G. (2011). Mode I fracture toughness of adhesively bonded joints as a function of temperature: Experimental and numerical study. Int J Adhes Adhes.31, pp. 273-9. DOI: 10.1016/j.ijadhadh.2010.09.005.

[13] BS 7991:2001 Standard. Determination of the mode I adhesive fracture energy, GIC, of structural adhesives using the double cantilever beam (DCB) and tapered double cantilever beam (TDCB) specimens. London, United Kingdom: British Standards Institution; 2001.

[14] ASTM D3433-99 Standard. Standard test method for fracture strength in cleavage of adhesives in bonded metal joints. West Conshohocken, PA: ASTM International; 2012. 
[15] ISO 25217 Standard. Adhesives - determination of the mode 1 adhesive fracture energy of structural adhesive joints using double cantilever beam and tapered double cantilever beam specimens. Geneva, Switzerland: International Organization for Standardization; 2009.

[16] Sistaninia, M., Sistaninia, M. (2015). Theoretical and experimental investigations on the mode II fracture toughness of brittle materials. International Journal of Mechanical Sciences.98, pp. 1-13.

DOI: 10.1016/j.ijmecsci.2015.04.003

[17] ASTM, D. (2001). 6671-01, Standard test method for mixed mode I-Mode II interlaminar fracture toughness of unidirectional fiber reinforced polymer matrix composites. Annual book of ASTM standards.15, pp. 03.

[18] Choupani, N. (2008). Mixed-mode cohesive fracture of adhesive joints: Experimental and numerical studies. Engineering Fracture Mechanics.75, pp. 4363-82. DOI: 10.1016/j.engfracmech.2008.04.023.

[19] Chaves, F.J.P., da Silva, L.F.M., de Moura, M.F.S.F., Dillard, D.A., Esteves, V.H.C. (2014). Fracture Mechanics Tests in Adhesively Bonded Joints: A Literature Review. J Adhesion.90, pp. 955-92. DOI: 10.1080/00218464.2013.859075.

[20] Rodrigues, T.A.F., Chaves, F.J.P., Silva, L.F.M.d., Costa, M., Barbosa, A.Q. (2017). Determination of the fracture envelope of an adhesive joint as a function of moisture. Materialwissenschaft und Werkstofftechnik.48, pp. 1181-90. DOI: doi:10.1002/mawe.201700571.

[21] Costa, M., Carbas, R., Marques, E., Viana, G., da Silva, L.F.M. (2017). An apparatus for mixed-mode fracture characterization of adhesive joints. Theor Appl Fract Mec.91, pp. 94-102. DOI: 10.1016/j.tafmec.2017.04.014.

[22] Nunes, F.A.A., Campilho, R.D.S.G. (2018). Mixed-mode fracture analysis of adhesively-bonded joints using the ATDCB test specimen. International Journal of Adhesion and Adhesives.85, pp. 58-68.

DOI: 10.1016/j.ijadhadh.2018.05.019.

[23] Rocha, R.J.B., Campilho, R.D.S.G. (2018). Evaluation of different modelling conditions in the cohesive zone analysis of single-lap bonded joints. J Adhesion.94, pp. 562-82. DOI: 10.1080/00218464.2017.1307107.

[24] Ribeiro, T.E.A., Campilho, R.D.S.G., da Silva, L.F.M., Goglio, L. (2016). Damage analysis of composite-aluminium adhesively-bonded single-lap joints. Compos Struct. 136, pp. 25-33.

DOI: $10.1016 /$ j.compstruct.2015.09.054

[25] Moreira, R.D.F., Campilho, R.D.S.G. (2015). Strength improvement of adhesively-bonded scarf repairs in aluminium structures with external reinforcements. Engineering Structures. 101, pp. 99-110.

DOI: 10.1016/j.engstruct.2015.07.001.

[26] Campilho, R.D.S.G., Banea, M.D., Pinto, A.M.G., da Silva, L.F.M., de Jesus, A.M.P. (2011). Strength prediction of single- and double-lap joints by standard and extended finite element modelling. Int J Adhes Adhes.31, pp. 363-72. DOI: $10.1016 /$ j.ijadhadh.2010.09.008

[27] Campilho, R.D.S.G., Banea, M.D., Neto, J.A.B.P., da Silva, L.F.M. (2013). Modelling adhesive joints with cohesive zone models: effect of the cohesive law shape of the adhesive layer. Int J Adhes Adhes.44, pp. 48-56.

DOI: 10.1016/j.ijadhadh.2013.02.006.

[28] Faneco, T., Campilho, R., Silva, F., Lopes, R. (2017). Strength and Fracture Characterization of a Novel Polyurethane Adhesive for the Automotive Industry. J Test Eval.45, pp. 398-407. DOI: 10.1520/JTE20150335.

[29] Markolefas, S.I., Papathanassiou, T.K. (2009). Stress redistributions in adhesively bonded double-lap joints, with elasticperfectly plastic adhesive behavior, subjected to axial lap-shear cyclic loading. Int J Adhes Adhes.29, pp. 737-44. DOI: 10.1016/j.ijadhadh.2009.04.001.

[30] André, A., Haghani, R., Biel, A. (2012). Application of fracture mechanics to predict the failure load of adhesive joints used to bond CFRP laminates to steel members. Construction and Building Materials.27, pp. 331-40. DOI: 10.1016/j.conbuildmat.2011.07.040.

[31] de Moura, M.F.S.F., Campilho, R.D.S.G., Gonçalves, J.P.M. (2009). Pure mode II fracture characterization of composite bonded joints. Int J Solids Struct.46, pp. 1589-95. DOI: 10.1016/j.ijsolstr.2008.12.001.

[32] Constante, C.J., Campilho, R.D.S.G., Moura, D.C. (2015). Tensile fracture characterization of adhesive joints by standard and optical techniques. Eng Fract Mech.136, pp. 292-304. DOI: 10.1016/j.engfracmech.2015.02.010.

[33] Fernández, M.V., de Moura, M.F.S.F., da Silva, L.F.M., Marques, A.T. (2013). Mixed-mode I + II fatigue/fracture characterization of composite bonded joints using the Single-Leg Bending test. Composites Part A: Applied Science and Manufacturing.44, pp. 63-9. DOI: 10.1016/j.compositesa.2012.08.009.

[34] Szekrényes, A., Uj, J. (2004). Beam and finite element analysis of quasi-unidirectional composite SLB and ELS specimens. Composites Science and Technology.64, pp. 2393-406.

DOI: 10.1016/j.compscitech.2004.05.002. 
[35] Kafkalidis, M.S., Thouless, M.D. (2002). The effects of geometry and material properties on the fracture of single lapshear joints. Int J Solids Struct.39, pp. 4367-83. DOI: 10.1016/S0020-7683(02)00344-X.

[36] Feraren, P., Jensen, H.M. (2004). Cohesive zone modelling of interface fracture near flaws in adhesive joints. Eng Fract Mech.71, pp. 2125-42. DOI: 10.1016/j.engfracmech.2003.12.003.

[37] Abaqus ${ }^{\circledR}$. Documentation of the software Abaqus ${ }^{\circledR}$. Dassault Systèmes. Vélizy-Villacoublay 2013.

[38] Ameli, A., Papini, M., Schroeder, J.A., Spelt, J.K. (2010). Fracture R-curve characterization of toughened epoxy adhesives. Eng Fract Mech.77, pp. 521-34. DOI: 10.1016/j.engfracmech.2009.10.009.

[39] Blackman, B.R.K., Kinloch, A.J., Rodriguez Sanchez, F.S., Teo, W.S., Williams, J.G. (2009). The fracture behaviour of structural adhesives under high rates of testing. Engineering Fracture Mechanics.76, pp. 2868-89. DOI: 10.1016/j.engfracmech.2009.07.013.

[40] Pardoen, T., Ferracin, T., Landis, C.M., Delannay, F. (2005). Constraint effects in adhesive joint fracture. J Mech Phys Solids.53, pp. 1951-83. DOI: 10.1016/j.jmps.2005.04.009.

[41] Nunes, S.L.S., Campilho, R.D.S.G., da Silva, F.J.G., de Sousa, C.C.R.G., Fernandes, T.A.B., Banea, M.D., et al. (2016). Comparative failure assessment of single and double-lap joints with varying adhesive systems. J Adhesion.92, pp. 61034. DOI: $10.1080 / 00218464.2015 .1103227$.

[42] Adams, R.D., Peppiatt, N.A. (1974). Stress analysis of adhesive-bonded lap joints. The Journal of Strain Analysis for Engineering Design.9, pp. 185-96. DOI: 10.1243/03093247v093185. 